\title{
Comparative Simulation Analysis of Dispersion Mitigation Techniques Using Symmetrical-DCF, FBG and CFBG in High Speed DWDM Networks
}

\author{
Abd El-Naser A. Mohammed \\ Electronics and Electrical \\ Communications Engineering \\ Department, Faculty of Electronic \\ Engineering, Menouf 32951 \\ Menoufia University.
}

\author{
Ahmed Nabih Zaki Rashed \\ Electronics and Electrical \\ Communications Engineering \\ Department, Faculty of Electronic \\ Engineering, Menouf 32951, \\ Menoufia University.
}

\author{
Fatma Mohammed Aref \\ Electronics and Electrical \\ Communications Engineering \\ Department, Faculty of Electronic \\ Engineering, Menouf 32951, \\ Menoufia University.
}

\begin{abstract}
The performance of the dense wavelength division multiplexing (DWDM) network is severely limited by the chromatic dispersion. So, it is crucial to mitigate and compensate this dispersion. In this paper, the different dispersion compensation techniques are discussed and compared. The DWDM system performance is evaluated by utilizing these dispersion mitigation techniques. The techniques used are dispersion compensation fiber (DCF) with symmetrical compensation scheme, Fiber Bragg Grating (FBG) and Chirped Fiber Bragg Grating (CFBG). The system performance is investigated for 16-channels DWDM network using Return-to-Zero (RZ) and Non-Return-toZero (NRZ) modulation formats over transmission distance up to $200 \mathrm{~km}$ at 2.5 and $5 \mathrm{~Gb} / \mathrm{s}$ data flow rate per channel. The system performance is evaluated according to Quality factor (Q-factor), Optical Signal to Noise Ratio (OSNR) and Signal to Noise Ratio (SNR) through Eye Diagrams. The DWDM network is implemented by using Optisystem simulator. The simulation results are outlined in tables indicating the most efficient dispersion compensation technique. The simulation results revealed that the systems using FBG as dispersion compensator offers better performance and larger Q-factor especially for longer transmission distance. FBG achieved Q-factor of approximately 38 and 62 which are the larger $Q$-factor values compared to other dispersion compensation methods at data rate of 2.5 Gb/s over $200 \mathrm{~km}$ fiber length for NRZ and RZ respectively. Furthermore, as data rate increases, the performance is reduced adversely due to pulse broadening causing interference with adjacent channels. Finally, the systems using RZ format provides better performance than those that using NRZ although, NRZ has less pulse broadening due to its reduced bandwidth.
\end{abstract}

\section{Introduction}

Dense wavelength division multiplexing (DWDM) is a promising technology utilized to enhance the capacity of the optical communication network and verify the enormous increasing growing demands for communication bandwidth and data rate [1]. It can transmit multiple information channels with different wavelengths simultaneously over the existing fiber $[2,3]$. The dispersion is the major problem that DWDM technique suffers. The dispersion leads to degradation of system performance causing broadening of light pulses [4]. As an optical pulse propagates through the fiber, it is delayed causing spreading of optical pulse, which adversely affects the system performance [5]. So, we must mitigate and compensate the dispersion employing different compensating techniques like Optical Phase Conjugation (OPC), Negative Dispersion Fiber (NDF), Dispersion Shifted Fiber (DSF), Dispersion Flattened Fiber (DFF), Electronic Dispersion Compensation (EDC) or electrical equalizer, Dispersion Compensation Fiber (DCF) Fiber Bragg Grating (FBG) and Chirped Fiber Bragg Grating (CFBG) [6]. FBG is commonly used to compensate the dispersion in optical communication system due to its low insertion loss [7]. DCFs are utilized to reduce the overall dispersion in the optical path as DCFs have higher negative dispersion coefficient and can be connected to single mode fibers (SMFs) having positive dispersion coefficient [8], where the high negative dispersion compensates for positive dispersion over large lengths of optical fiber cable. According to the location of DCF, the compensation schemes can be pre-compensation, post-compensation and symmetrical-compensation [9-11].

Dispersion is the broadening of light pulses as they travel through fiber because of the difference in the group velocity of different modes [12]. The group velocity causes group velocity dispersion (GVD), which leads to a short pulse of light to spread in time as a result of different frequency components of the pulse propagating at different velocities [13]. It decreases the energy contain in the pulse, and hence pulse spreading creating inter symbol interference (ISI) with adjacent pulses and a reduction of the signal to noise ratio (SNR) [14]. Hence, it increases the Bit Error Rate (BER). Dispersion causes big distortions leading to errors [15]. The dispersion in DWDM systems increases the optical fiber nonlinearities. The longer the optical signal transmission length, the larger the fiber dispersion coefficient, the greater pulse broadening [16].

Dispersion compensation is the process of designing the fiber and compensating element in the transmission link minimizing the overall dispersion. There are three dispersion compensation schemes; (Pre, Post, and Symmetrical) compensation according to the DCF position in the path whether the DCF is positioned before the SMF or after the SMF or symmetrically across the SMF. Symmetrical compensation scheme reduce greatly the fiber 
nonlinearities [17]. The simulation circuit for dispersion compensation by using symmetrical DCF is proposed where the DCF is used before and after the optical fiber. The fiber is connected to a shorter length of a DCF; which is SMF with large negative dispersion; to compensate for the accumulated positive dispersion of SMF after every span. DCF have high negative dispersion of -70 to $-100 \mathrm{ps} / \mathrm{nm} . \mathrm{km}$ [18]. The commonly DCF length required is around 4 times SMF shorter than the transmission fiber length. The ideal case for dispersion compensation is given by following equation; the total dispersion will be zero [19]:

$$
\mathrm{D}_{\mathrm{SMF}} \times \mathrm{L}_{\mathrm{SMF}}=-\mathrm{D}_{\mathrm{DCF}} \times \mathrm{L}_{\mathrm{DCF}}
$$

where $\mathrm{D}_{\mathrm{SMF}}$ and $\mathrm{L}_{\mathrm{SMF}}$ are the dispersion and length of SMF. $\mathrm{D}_{\mathrm{DCF}}$ and $\mathrm{L}_{\mathrm{DCF}}$ are the dispersion and length of $\mathrm{DCF}$ respectively.

FBG executes reflection and filtering with high efficiency and low losses. FBG is a dispersion compensator in long-haul DWDM. There are two types of FBG (uniform FBG and CFBG) [20]. In a uniform FBG, the refractive index variation is constant along the length. For chromatic dispersion compensation, it is preferred to use a CFBG which depends on non-uniform variation of refractive index. The chirped grating can be made so that all wavelengths in the light pulse exit the reflector at the same time and the chromatic dispersion in the optical pulse accumulated along the fiber link is equalized [21]. A grating will reflect light with a Bragg's wavelength corresponding to twice the grating period $\Lambda$ multiplied by the effective refractive index $\eta_{\text {eff. }}$ This is called Bragg condition [22]. The equation represents the reflected wavelength $\lambda_{B}$ and depends on the effective refractive index of the medium $\eta_{\text {eff }}$ and can be obtained by following equation [23]:

$$
\lambda_{\mathrm{B}}=2 \mathrm{n}_{\mathrm{eff}} \Lambda
$$

where $\lambda_{B}$ is the Bragg wavelength, $n_{\text {eff }}$ is the effective group refractive index of core and $\Lambda$ is the grating period of fiber. In [24], authors implemented 8-channels DWDM system utilizing symmetrical-DCF and Optigrating for dispersion compensation by using NRZ modulation format. They compared the system performance by using symmetricalDCF and Optigrating. They found that symmetrical-DCF is better than Optigrating. In [25], FBG has been used for dispersion compensation over different transmission distances for NRZ at $20 \mathrm{~Gb} / \mathrm{s}$. It was revealed that the signal quality slightly changed over longer transmission distance when using FBG. So, FBG is preferred especially for longer fiber lengths. In [26], the effects of applying different input power levels on the system performance in case of using FBG as a dispersion compensator have been studied in details. It was found that as the power level increases, the fiber nonlinearity effects are also increasing. In this paper, the 16-channels DWDM system is implemented by Optisystem simulator employing different dispersion compensation techniques at $2.5 \mathrm{~Gb} / \mathrm{s}$ and $5 \mathrm{~Gb} / \mathrm{s}$ for RZ and NRZ modulation formats over different transmission distance up to $200 \mathrm{~km}$. The techniques used are the symmetrical-DCF, FBG and CFBG. Furthermore, the effect of different input power levels has been deeply discussed.
The performance is measured according to Q-factor, SNR and OSNR.

The paper is organized as the following. The experiment setup and parameters are described and listed in Section 2. This is followed by Section 3; where the simulation results are discussed, listed in tables and drawn. The system performance is compared for different compensation techniques. Finally, the conclusions of the paper are outlined in Section 4.

\section{Experiment Setup}

Long-reach 16-channels DWDM network is proposed and simulated by Optisystem. The long-haul DWDM system is modeled for 16-channels spaced at $100 \mathrm{GHz}$ for 2.5 and 5 $\mathrm{Gb} / \mathrm{s}$ channel speeds through Single Mode Fiber (SMF) over transmission distance up to $200 \mathrm{~km}$. The simulation is executed for $100 \mathrm{~km}$ and $200 \mathrm{~km}$. The DWDM system is examined by varying the input power level from $-5 \mathrm{~dB}_{\mathrm{m}}$ to $15 \mathrm{~dB}_{\mathrm{m}}$. In this paper, the system performance is investigated and compared for different dispersion compensation techniques which are symmetrical-DCF, FBG and CFBG. An optical communication network consists of a transmitter, propagation path and receiver. The optical transmitter launches the optical signals through the propagation path; optical fiber. The optical receiver converts the attenuated optical signals into electrical signals to recover the original data. The simulation models of 16channels DWDM network for different dispersion compensation techniques are shown in figures $(1-3)$. The system simulation parameters assigned for each component are outlined in Table (1).

The optical transmitter section side consists of DWDM transmitter and DWDM Multiplexer. The DWDM transmitter generates optical signals with certain wavelengths at 16 output ports for 16-channels equally spaced at $100 \mathrm{GHz}$. The frequency of emission ranges from 193.1 THz to $194.6 \mathrm{THz}$ with $10 \mathrm{MHz}$ line width. Channels emit wavelengths: $1553.599 \mathrm{~nm}, 1552.795 \mathrm{~nm}$ and 1551.199 $\mathrm{nm}$ respectively up to the $16^{\text {th }}$ channel which emits $1541.623 \mathrm{~nm}$. Each channel transmits 2.5 and $5 \mathrm{~Gb} / \mathrm{s}$ data rate. The data is transmitted in NRZ format. The power level emitted is varied from $-5 \mathrm{~dB}_{\mathrm{m}}$ to $15 \mathrm{~dB}_{\mathrm{m}}$. The sixteen optical output signals from DWDM transmitter are multiplexed onto a single fiber by DWDM Multiplexer $(16 \times 1)$ with zero insertion loss. DWDM Multiplexer is placed at the transmitter end. It combines the laser wavelength channels into one polychromatic signal for transmission through the single optical fiber. On the same way, there is a $(1 \times 16)$ DWDM Demultiplexer which is connected to the beginning of the receiver side at the remote end of the path. It is added in order to separate the channels combined by the DWDM Multiplexer into their original wavelengths and split them apart; so they can be detected individually. 
Table (1): The Parameters assigned for the Components used in the System Simulations of the DWDM Network.

\begin{tabular}{|c|c|c|c|c|c|}
\hline \multirow{2}{*}{\multicolumn{2}{|c|}{ Section }} & \multirow{2}{*}{ Components } & \multicolumn{3}{|c|}{ Parameters } \\
\hline & & & Type & Value & Unit \\
\hline \multirow{3}{*}{\multicolumn{2}{|c|}{$\begin{array}{l}\text { The Optical } \\
\text { Transmitter: }\end{array}$}} & \multirow{3}{*}{$\begin{array}{l}\text { 1) Optical DWDM } \\
\text { Transmitter (16 } \\
\text { Channels): }\end{array}$} & Channel Spacing: & 100 & $\mathrm{GHz}$ \\
\hline & & & Modulation Type: & $\begin{array}{l}\mathrm{RZ} \text { and } \\
\mathrm{NRZ}\end{array}$ & \\
\hline & & & Linewidth: & 10 & $\mathrm{MHz}$ \\
\hline \multirow{10}{*}{\multicolumn{2}{|c|}{$\begin{array}{l}\text { The Optical } \\
\text { Transmission } \\
\text { Path: }\end{array}$}} & \multirow{5}{*}{$\begin{array}{l}\text { 2) Optical fiber } \\
\text { (SMF): }\end{array}$} & Fiber Length per Span: & $\begin{array}{c}100 \mathrm{~km} \text { and } \\
200 \mathrm{~km}\end{array}$ & $\mathrm{~km}$ \\
\hline & & & Dispersion (GVD): & 17 & $\mathrm{ps} / \mathrm{nm} / \mathrm{km}$ \\
\hline & & & Dispersion Slope (S): & 0.07 & $\mathrm{ps} / \mathrm{nm}^{2} / \mathrm{km}$ \\
\hline & & & Attenuation $(\alpha)$ : & 0.2 & $\mathrm{~dB} / \mathrm{km}$ \\
\hline & & & Effective Area (A): & 80 & $\mu \mathrm{m}^{2}$ \\
\hline & & \multirow{5}{*}{$\begin{array}{l}\text { 3) Optical fiber } \\
\text { (DCF): }\end{array}$} & Fiber Length per Span: & 10 & $\mathrm{~km}$ \\
\hline & & & Dispersion (GVD): & -85 & $\mathrm{ps} / \mathrm{nm} / \mathrm{km}$ \\
\hline & & & Dispersion Slope (S): & -0.3 & $\mathrm{ps} / \mathrm{nm}^{2} / \mathrm{km}$ \\
\hline & & & Attenuation $(\alpha)$ : & 0.5 & $\mathrm{~dB} / \mathrm{km}$ \\
\hline & & & Effective Area (A): & 80 & $\mu \mathrm{m}^{2}$ \\
\hline \multirow{12}{*}{\multicolumn{2}{|c|}{$\begin{array}{l}\text { The Optical } \\
\text { Receiver: }\end{array}$}} & \multirow{3}{*}{$\begin{array}{l}\text { 4) Fiber Bragg } \\
\text { Grating (FBG): }\end{array}$} & Depth: & 100 & $\overline{\mathrm{dB}}$ \\
\hline & & & Dispersion: & -1700 & $\mathrm{ps} / \mathrm{nm}$ \\
\hline & & & Insertion Loss: & 0 & $\mathrm{~dB}$ \\
\hline & & \multirow{5}{*}{$\begin{array}{l}\text { 5) Chirped Fiber } \\
\text { Bragg Grating } \\
\text { (CFBG): }\end{array}$} & Effective Index: & 1.46 & \\
\hline & & & Length: & 6 & $\mathrm{~mm}$ \\
\hline & & & Modulation Ac: & 0.0001 & \\
\hline & & & Number of Segments: & 101 & \\
\hline & & & Noise Dynamic: & 3 & $\mathrm{~dB}$ \\
\hline & & \multirow{2}{*}{$\begin{array}{l}\text { 6) Optical amplifier } \\
\text { (Ideal EDFA): }\end{array}$} & Gain: & 35 & $\overline{\mathrm{dB}}$ \\
\hline & & & Noise Figure: & 0 & $\mathrm{~dB}$ \\
\hline & & \multirow{2}{*}{$\begin{array}{c}\text { 7) APD } \\
\text { photodetectors: }\end{array}$} & Responsivity: & 0.9 & 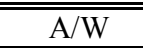 \\
\hline & & & Dark Current: & 10 & $\mathrm{nA}$ \\
\hline \multirow{8}{*}{\multicolumn{2}{|c|}{ 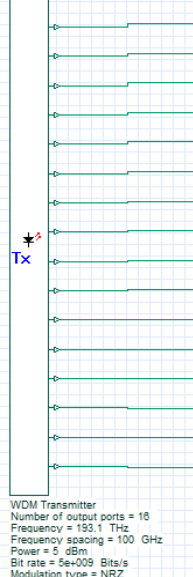 }} & \multirow{8}{*}{ 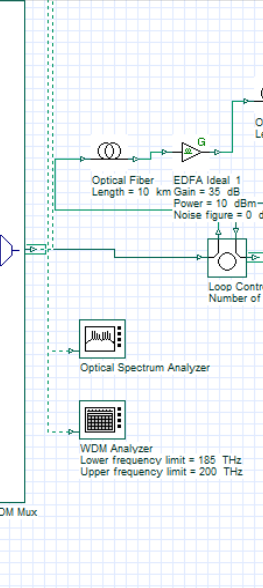 } & $\Rightarrow \rightarrow{ }^{a} \rightarrow$ & \multicolumn{2}{|c|}{ 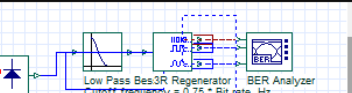 } \\
\hline & & & 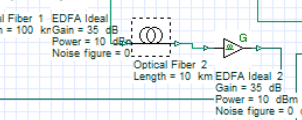 & 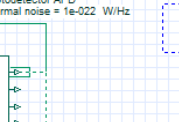 & \multirow[t]{2}{*}{ 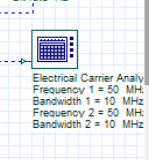 } \\
\hline & & & & $N:$ & \\
\hline & & & 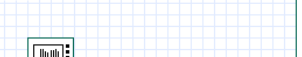 & $\Rightarrow$ & \\
\hline & & & 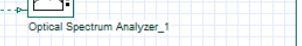 & $-\infty$ & \\
\hline & & & 濶: & 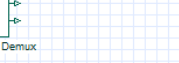 & \\
\hline & & & 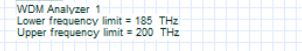 & & \\
\hline & & & & & \\
\hline
\end{tabular}

Figure (1) The Simulation of 16-channels DWDM Network utilizing the Symmetrical-DCF Dispersion Compensation Technique.

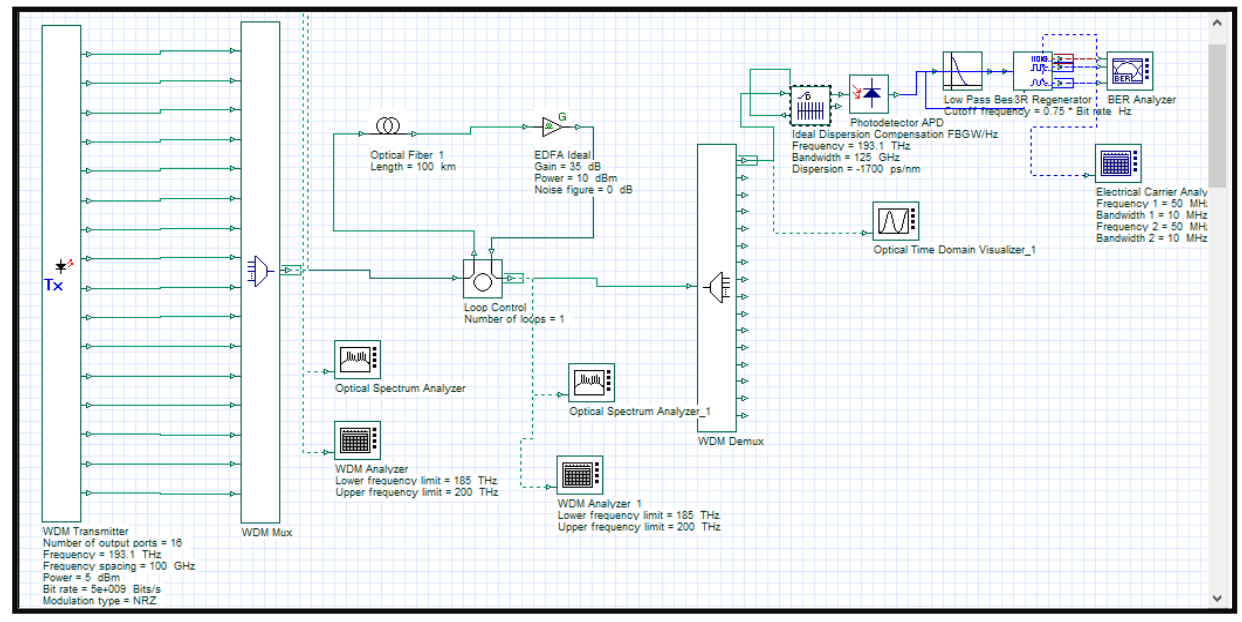

Figure (2) The Simulation of 16-channels DWDM Network utilizing the FBG Dispersion Compensation Technique. 
The multiplexed signals are sent over the optical transmission path. It is designed as a distance of $200 \mathrm{~km}$ $(100 \mathrm{~km} \times 2$ loops). Erbium doped fiber amplifier (EDFA) optical fiber amplifier is used for signal amplification. The span design is utilized to achieve dispersion compensation. The loop control mechanism is applied to increase the transmission distance that the optical signal travel. The output from the 16-channels DWDM Multiplexer $(16 \times 1)$ is fed to loop control component in the optical transmission path. The simulation models utilize different dispersion compensation techniques which are Symmetrical-DCF, FBG and CFBG. Figures from (1) - (3) show the simulation models for these mitigation techniques respectively. Finally, the signal tour trip goes towards to the loop control and then enters to the receiver side through the DWDM Demultiplexer terminated to the photodetector.

The optical receiver section side generally consists of DWDM Demultiplexer $(1 \times 16)$ and a set of 16 singlechannel receiver connected to its each output port. The receiver contains DWDM Demultiplexer $(1 \times 16)$, APD photodetectors, Low-Pass Bessel filters, 3R Regenerators Electrical Carrier analyzers and BER analyzers. After the loop control, there is an optical DWDM Demultiplexer $(1 \times 16)$ whose channels operate at the same preassigned frequencies as the DWDM Multiplexer. The amplified combined signals are split and demultiplexed by DWDM Demultiplexer into their 16 individual wavelengths that have been assigned before at each channel. The outputs of the DWDM Demultiplexer are fed into APD photodetectors. They detect the incident optical signals and convert them back into their electrical counterpart signals via the photoelectric effect. The photodetector utilized is APD with responsivity $0.9 \mathrm{~A} / \mathrm{W}$. It has dark current of $10 \mathrm{nA}$. Thermal noise level is adjusted to $10^{-22} \mathrm{~W} / \mathrm{Hz}$ for each photodetector. Practical receivers have thermal noise levels in the range of $10^{-24} \mathrm{~W} / \mathrm{Hz}$ up to $10^{-20} \mathrm{~W} / \mathrm{Hz}$ [27]. The common noises such as the Amplified Spontaneous Emission (ASE) and shot noise are applied to the setup to be actual. Each converted electrical signal by a photodetector is filtered by a fourth order Low Frequency Pass Bessel Filter (LPBF) to reduce the noise part of the electrical signal. The LPBF is followed by $3 \mathrm{R}$ Regenerator which performs three processes referred to as Re-amplification, Re-shaping, and Re-timing to regenerate the electrical signal corresponding to the original bit sequence perfectly. The three terminals outputs from $3 \mathrm{R}$ Regenerator are connected directly to BER analyzer to generate eye diagrams and measure the system performance. By visualizing Eye diagrams, many parameters like Q-factor and BER are computed for each received channel.

\section{Simulation Results and Performance Analysis}

The 16-channels DWDM network is implemented utilizing different dispersion compensation techniques; symmetrical-DCF, FBG and CFBG. The performance of these techniques is evaluated using Opisystem. It is compared according to Q-factor, OSNR and SNR. BER analyzer displays the Eye diagrams which include the Qfactor for each channel. SNR calculations are executed by Electrical Carrier analyzer. At the receiver section, the performance of one of the 16 channels (Channel 1:193.1 $\mathrm{THz}$ ) is evaluated using the performance evaluation parameters. The system performance is tested for various input power levels from $-5 \mathrm{~dB}_{\mathrm{m}}$ to $15 \mathrm{~dB}_{\mathrm{m}}$ over $100 \mathrm{~km}$ and $200 \mathrm{~km}$ fiber lengths based on the channel speed, the type of modulation scheme and the type of dispersion compensation technique used. Also, the variation in input power level is studied at $100 \mathrm{~km}$. The simulation results are tabulated, drawn and compared for different modulation schemes (RZ and NRZ) and different dispersion compensation techniques. Tables (2-11) summarize the obtained results including a comparison between the used techniques for the system evaluation parameters, which are Q-factor, OSNR and $\mathrm{SNR}$ at $2.5 \mathrm{~Gb} / \mathrm{s}$ and $5 \mathrm{~Gb} / \mathrm{s}$ for RZ and NRZ over different transmission lengths up to $200 \mathrm{~km}$. From experimental results which listed in tables and drawn in figures; the following observations can be discussed:

i) From Table (2); the FBG is the most efficient technique for dispersion mitigation because the system provides better performance in terms of higher Q-factor. FBG is followed by CFBG for longer transmission distance then finally symmetrical-DCF.

ii) From Table (3), it is shown that the OSNR does not change for all dispersion compensation techniques at the same transmission distance.

iii) The SNR values are listed in Table (4), the system offers higher performance when using FBG as a dispersion compensator based on its larger Q-factor values for both modulation formats over $100 \mathrm{~km}$ and $200 \mathrm{~km}$. This is followed by CFBG, then finally symmetrical-DCF.

IV) RZ modulation scheme is superior to NRZ where the performance is higher due to higher Q-factor and larger SNR as shown in Tables (2-4). However, RZ requires doubled pulse bandwidth than NRZ causing more pulse broadening but it is the better when detecting successive ones.

V) As well known, as the data rate is increasing, the system performance is degraded when utilizing all dispersion mitigation techniques with both modulation schemes as indicated in Tables $(2-4)$ where lower Q-factor and smaller SNR are obtained.

VI) It is clearly that as the transmission distance is increasing, the performance is reduced according to lower Q-factor and smaller SNR because the dispersion is increased as observed in Tables $(2-4)$.

VII) The Table (5) includes the Eye Diagrams of channel 1:193.1 THz for symmetrical-DCF, FBG and CFBG dispersion mitigation techniques utilizing $\mathrm{RZ}$ and NRZ modulation schemes for $200 \mathrm{~km}$ fiber length with data rates 2.5 and $5 \mathrm{~Gb} / \mathrm{s}$ at $\mathrm{P}_{\text {in }}=5 \mathrm{~dB}_{\mathrm{m}}$.

VIII) It is noted from Eye Patterns that the Eye Diagrams generated from systems utilizing FBG are more clearer and wider; this means less noise and hence better performance, thus best quality for the transmitted signal and most efficient system. Also, it can be seen obviously that the Eye Diagrams of systems using RZ format are more pure and wider.

IX) From Tables $(6-11)$ and Figures (4 and 5), it can be observed that as the input power is increasing, the system performance can be enhanced as both the Q-factor and SNR are increased when using all dispersion compensation techniques for both modulation schemes with both data rates $2.5 \mathrm{~Gb} / \mathrm{s}$ and $5 \mathrm{~Gb} / \mathrm{s}$ at $100 \mathrm{~km}$ transmission distance. 


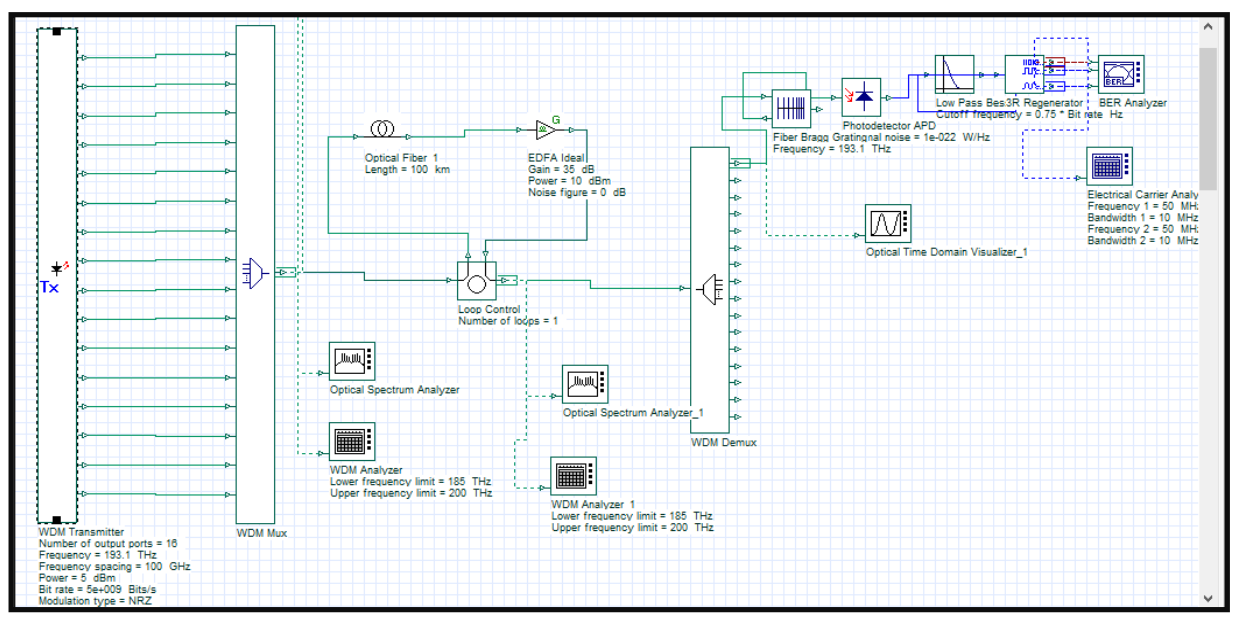

Figure (3) The Simulation of 16-channels DWDM Network utilizing the CFBG Dispersion Compensation Technique.

Table (2): The Q-Factor of channel 1 (193.1 THz) for Symmetrical-DCF, FBG and CFBG dispersion compensation techniques utilizing RZ and NRZ modulation formats over $100 \mathrm{~km}$ and $200 \mathrm{~km}$ fiber lengths with data rates $2.5 \mathrm{~Gb} / \mathrm{s}$ and $5 \mathrm{~Gb} / \mathrm{s}$ at $\mathrm{P}_{\text {in }}=5 \mathrm{dBm}$.

\begin{tabular}{|c|c|c|c|c|c|}
\hline \multirow[b]{2}{*}{ Data Rate } & \multirow{2}{*}{$\begin{array}{c}\text { Modulation Format } \\
\text { Dispersion } \\
\text { Compensation } \\
\text { Technique }\end{array}$} & \multicolumn{2}{|c|}{ RZ } & \multicolumn{2}{|c|}{ NRZ } \\
\hline & & $100 \mathrm{~km}$ & $200 \mathrm{~km}$ & $100 \mathrm{~km}$ & $200 \mathrm{~km}$ \\
\hline \multirow{3}{*}{$2.5 \mathrm{~Gb} / \mathrm{s}$} & Symmetrical-DCF & 98.66 & 38.35 & 50.95 & 25.85 \\
\hline & FBG & 37.52 & 62.50 & 28.45 & 37.88 \\
\hline & CFBG & 86.37 & 36.37 & 45.88 & 29.45 \\
\hline \multirow{3}{*}{$5 \mathrm{~Gb} / \mathrm{s}$} & Symmetrical-DCF & 170.14 & 28.04 & 35.53 & 24.39 \\
\hline & FBG & 41.68 & 69.70 & 24.80 & 31.07 \\
\hline & CFBG & 161.51 & 32.64 & 31.44 & 24.51 \\
\hline
\end{tabular}

Table (3): The OSNR of channel 1 (193.1 THz) for Symmetrical-DCF, FBG and CFBG dispersion compensation techniques utilizing RZ and NRZ modulation formats over $100 \mathrm{~km}$ and $200 \mathrm{~km}$ fiber lengths with data rates $2.5 \mathrm{~Gb} / \mathrm{s}$ and $5 \mathrm{~Gb} / \mathrm{s}$ at $\mathrm{P}_{\text {in }}=5 \mathrm{dBm}$.

\begin{tabular}{|c|c|c|c|c|c|}
\hline \multirow[b]{2}{*}{ Data Rate } & \multirow{2}{*}{$\begin{array}{c}\text { Modulation Format } \\
\text { Dispersion } \\
\text { Compensation } \\
\text { Technique }\end{array}$} & \multicolumn{2}{|c|}{ RZ } & \multicolumn{2}{|c|}{ NRZ } \\
\hline & & $100 \mathrm{~km}$ & $200 \mathrm{~km}$ & $100 \mathrm{~km}$ & $200 \mathrm{~km}$ \\
\hline \multirow{3}{*}{$2.5 \mathrm{~Gb} / \mathrm{s}$} & "Symmetrical-DCF & "65.86 & 34.64 & 711.86 & 37.01 \\
\hline & FBG & 65.86 & 37.54 & 71.86 & 39.91 \\
\hline & CFBG & 65.86 & 37.54 & 71.86 & 39.91 \\
\hline \multirow{3}{*}{$5 \mathrm{~Gb} / \mathrm{s}$} & "Symmetrical-DCF & 63.26 & 34.77 & \begin{tabular}{c|}
68.41 \\
\end{tabular} & 37.26 \\
\hline & FBG & 63.26 & 37.61 & 68.41 & 40.23 \\
\hline & CFBG & 63.26 & 37.61 & 68.41 & 40.23 \\
\hline
\end{tabular}

Table (4): The SNR of channel 1 (193.1 THz) for Symmetrical-DCF, FBG and CFBG dispersion compensation techniques utilizing RZ and NRZ modulation formats over $100 \mathrm{~km}$ and $200 \mathrm{~km}$ fiber lengths with data rates $2.5 \mathrm{~Gb} / \mathrm{s}$ and $5 \mathrm{~Gb} / \mathrm{s}$ at $\mathrm{P}_{\text {in }}=5 \mathrm{dBm}$.

\begin{tabular}{|c|c|c|c|c|c|}
\hline \multirow[b]{2}{*}{ Data Rate } & \multirow{2}{*}{$\begin{array}{c}\text { Modulation Format } \\
\text { Dispersion } \\
\text { Compensation } \\
\text { Technique }\end{array}$} & \multicolumn{2}{|c|}{ RZ } & \multicolumn{2}{|c|}{ NRZ } \\
\hline & & $100 \mathrm{~km}$ & $200 \mathrm{~km}$ & $100 \mathrm{~km}$ & $200 \mathrm{~km}$ \\
\hline \multirow{3}{*}{$2.5 \mathrm{~Gb} / \mathrm{s}$} & "Symmetrical-DCF & 55.60 & 26.46 & 57.50 & 33.90 \\
\hline & FBG & 55.65 & 43.05 & 62.03 & 48.06 \\
\hline & CFBG & 53.61 & 42.85 & 55.74 & 48.18 \\
\hline \multirow{3}{*}{$5 \mathrm{~Gb} / \mathrm{s}$} & "Symmetrical-DCF & 49.20 & 19.94 & 53.37 & 26.70 \\
\hline & FBG & 48.60 & 38.11 & 55 & 40.93 \\
\hline & CFBG & 48.38 & 35.96 & 51.46 & 39.15 \\
\hline
\end{tabular}


Table (5): The Eye Diagrams of channel 1 (193.1 THz) for Symmetrical-DCF, FBG and CFBG dispersion compensation techniques utilizing RZ and NRZ modulation formats over $200 \mathrm{~km}$ fiber length with data rates $2.5 \mathrm{~Gb} / \mathrm{s}$ and $5 \mathrm{~Gb} / \mathrm{s}$ at $\mathrm{P}_{\text {in }}=5 \mathrm{dBm}$.

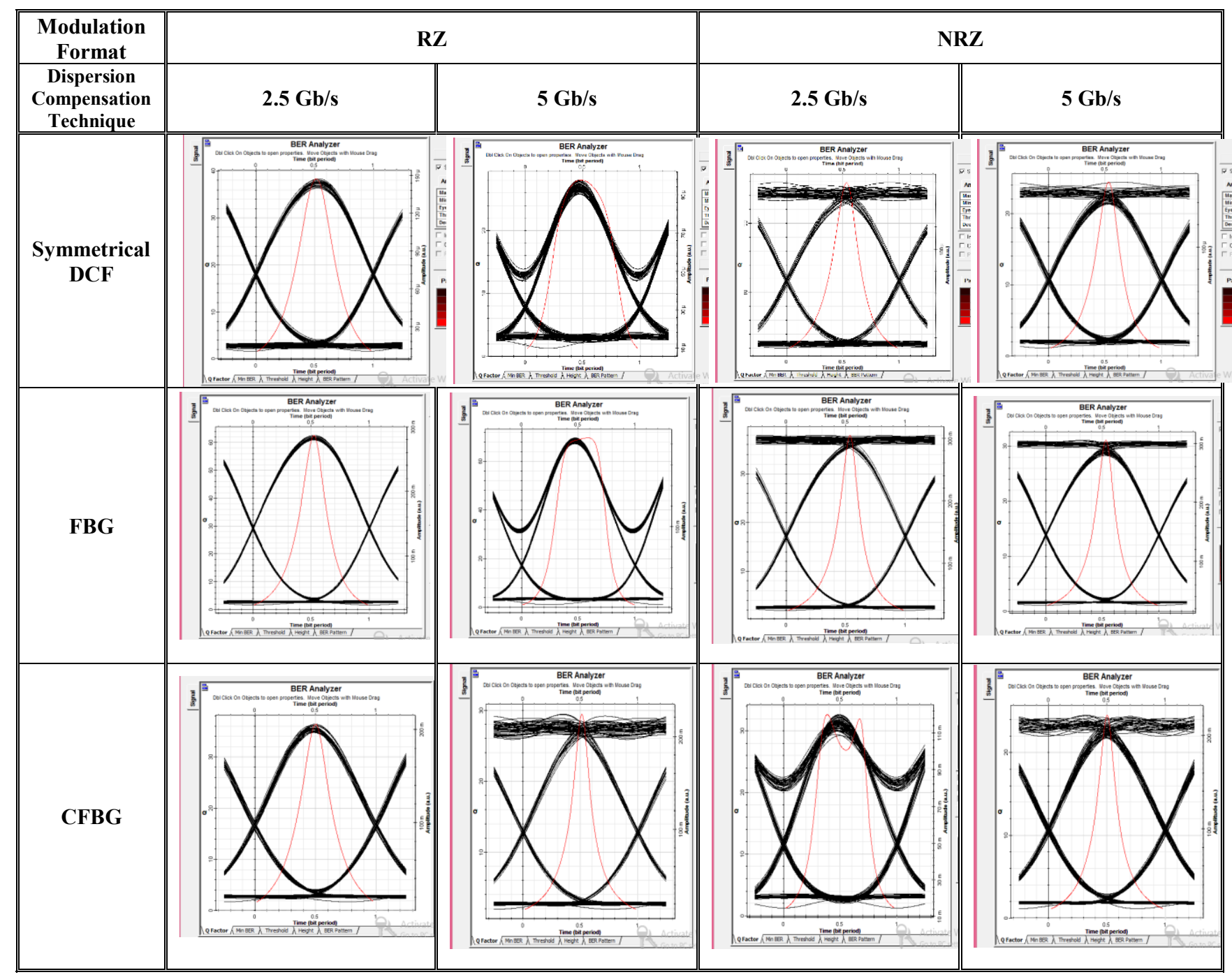

Table (6): The Q-Factor of channel 1:193.1 THz for Symmetrical-DCF, FBG and CFBG dispersion mitigation techniques using RZ format over $100 \mathrm{~km}$ length with data rates 2.5 and $5 \mathrm{~Gb} / \mathrm{s}$ at different input power levels.

\begin{tabular}{|c||c|c||c|c||c|c||}
\hline $\begin{array}{c}\text { Dispersion } \\
\text { Compensation } \\
\text { Technique }\end{array}$ & \multicolumn{2}{|c||}{ Symmetrical-DCF } & \multicolumn{2}{c||}{ FBG } & \multicolumn{2}{c||}{ CFBG } \\
\hline $\begin{array}{c}\text { Input Power } \\
\text { Level }\end{array}$ & $\mathbf{2 . 5 ~ G b / s}$ & $\mathbf{5 ~ G b / s}$ & $\mathbf{2 . 5} \mathbf{~ G b / s}$ & $\mathbf{5 ~ G b / s}$ & $\mathbf{2 . 5} \mathbf{~ G b} / \mathbf{s}$ & $\mathbf{5 ~ G b} / \mathbf{s}$ \\
\hline \hline $\mathbf{- 5 ~ d B m}$ & 76.33 & 91.94 & 36.08 & 39.41 & 64.67 & 80.66 \\
\hline $\mathbf{0 ~ d B m}$ & 90.09 & 134.14 & 37.19 & 41.29 & 77.83 & 123.52 \\
\hline $\mathbf{5 ~ d B m}$ & 98.66 & 170.14 & 37.52 & 41.68 & 86.37 & 161.51 \\
\hline $\mathbf{1 0 ~ d B m}$ & 102.88 & 193.10 & 37.61 & 41.72 & 90.96 & 187.18 \\
\hline $\mathbf{1 5} \mathbf{d B m}$ & 104.40 & 207.14 & 37.63 & 41.68 & 92.85 & 199.76 \\
\hline
\end{tabular}

Table (7): The OSNR of channel 1:193.1 THz for Symmetrical-DCF, FBG and CFBG dispersion mitigation techniques using RZ format over $100 \mathrm{~km}$ length with data rates 2.5 and $5 \mathrm{~Gb} / \mathrm{s}$ at different input power levels.

\begin{tabular}{|c||c|c||c|c||c|c||}
\hline $\begin{array}{c}\text { Dispersion } \\
\text { Compensation } \\
\text { Technique }\end{array}$ & \multicolumn{2}{|l||}{ Symmetrical-DCF } & \multicolumn{2}{|c||}{ FBG } & \multicolumn{2}{c||}{ CFBG } \\
\hline $\begin{array}{c}\text { Input Power } \\
\text { Level }\end{array}$ & $\mathbf{2 . 5} \mathbf{~ G b / s}$ & $\mathbf{5 ~ G b / s}$ & $\mathbf{2 . 5} \mathbf{~ G b} / \mathbf{s}$ & $\mathbf{5 ~ G b / s}$ & $\mathbf{2 . 5} \mathbf{~ G b / s}$ & $\mathbf{5 ~ G b} / \mathbf{s}$ \\
\hline \hline $\mathbf{- 5 ~ d B m}$ & 65.86 & 63.26 & 65.86 & 63.26 & 65.86 & 63.26 \\
\hline $\mathbf{0 ~ d B m}$ & 65.86 & 63.26 & 65.86 & 63.26 & 65.86 & 63.26 \\
\hline $\mathbf{5 ~ d B m}$ & 65.86 & 63.26 & 65.86 & 63.26 & 65.86 & 63.26 \\
\hline $\mathbf{1 0 ~ d B m}$ & 65.86 & 63.26 & 65.86 & 63.26 & 65.86 & 63.26 \\
\hline $\mathbf{1 5} \mathbf{~ d B m}$ & 65.86 & 63.26 & 65.86 & 63.26 & 65.86 & 63.26 \\
\hline \hline
\end{tabular}


Table (8): The SNR of channel 1:193.1 THz for Symmetrical-DCF, FBG and CFBG ispersion mitigation techniques using RZ format over $100 \mathrm{~km}$ length with data rates 2.5 and $5 \mathrm{~Gb} / \mathrm{s}$ at different input power levels.

\begin{tabular}{|c||c|c||c|c||c|c||}
\hline $\begin{array}{c}\text { Dispersion } \\
\text { Compensation } \\
\text { Technique }\end{array}$ & \multicolumn{2}{|l||}{ Symmetrical-DCF } & \multicolumn{2}{|c||}{ FBG } & \multicolumn{2}{c||}{ CFBG } \\
\hline $\begin{array}{c}\text { Input Power } \\
\text { Level }\end{array}$ & $\mathbf{2 . 5 ~ G b / s}$ & $\mathbf{5 ~ G b / s}$ & $\mathbf{2 . 5} \mathbf{~ G b} / \mathbf{s}$ & $\mathbf{5 ~ G b / s}$ & $\mathbf{2 . 5} \mathbf{~ G b} / \mathbf{s}$ & $\mathbf{5 ~ G b} / \mathbf{s}$ \\
\hline \hline $\mathbf{- 5} \mathbf{~ d B m}$ & 42.68 & 36.08 & 42.68 & 36.08 & 39.57 & 32.96 \\
\hline $\mathbf{0 ~ d B m}$ & 50.31 & 44.18 & 50.47 & 43.35 & 48.27 & 42.96 \\
\hline $\mathbf{5 ~ d B m}$ & 55.60 & 49.20 & 55.65 & 48.60 & 53.61 & 48.38 \\
\hline $\mathbf{1 0 ~ d B m}$ & 60.76 & 54.20 & 60.74 & 53.74 & 58.80 & 53.46 \\
\hline $\mathbf{1 5} \mathbf{d B m}$ & 65.85 & 64.20 & 65.79 & 58.82 & 63.90 & 58.50 \\
\hline
\end{tabular}

Table (9): The Q-Factor of channel 1:193.1 THz for Symmetrical-DCF, FBG and CFBG dispersion mitigation techniques using NRZ format over $100 \mathrm{~km}$ length with data rates 2.5 and $5 \mathrm{~Gb} / \mathrm{s}$ at different input power levels.

\begin{tabular}{|c||c|c||c|c||c|c||}
\hline $\begin{array}{c}\text { Dispersion } \\
\text { Compensation } \\
\text { Technique }\end{array}$ & \multicolumn{2}{|c||}{ Symmetrical-DCF } & \multicolumn{2}{c||}{ FBG } & \multicolumn{2}{c||}{ CFBG } \\
\hline $\begin{array}{c}\text { Input Power } \\
\text { Level }\end{array}$ & $\mathbf{2 . 5} \mathbf{~ G b / s}$ & $\mathbf{5 ~ G b / s}$ & $\begin{array}{c}\mathbf{2 . 5} \\
\text { Gb/s }\end{array}$ & $\mathbf{5 ~ G b / s}$ & $\mathbf{2 . 5} \mathbf{G b} / \mathbf{s}$ & $\mathbf{5}$ Gb/s \\
\hline \hline $\mathbf{- 5} \mathbf{~ d B m}$ & 49.09 & 34.26 & 28.11 & 24.60 & 44.34 & 30.17 \\
\hline $\mathbf{0 ~ d B m}$ & 50.64 & 35.18 & 28.39 & 24.74 & 45.74 & 31.11 \\
\hline $\mathbf{5} \mathbf{~ d B m}$ & 50.95 & 35.53 & 28.45 & 24.80 & 45.88 & 31.44 \\
\hline $\mathbf{1 0 ~ d B m}$ & 50.95 & 35.68 & 28.46 & 24.83 & 45.78 & 31.56 \\
\hline $\mathbf{1 5} \mathbf{~ d B m}$ & 50.90 & 35.75 & 28.45 & 24.84 & 45.68 & 31.61 \\
\hline
\end{tabular}

Table (10): The OSNR of channel 1:193.1 THz for Symmetrical-DCF, FBG and CFBG dispersion mitigation techniques using NRZ format over $100 \mathrm{~km}$ length with data rates 2.5 and $5 \mathrm{~Gb} / \mathrm{s}$ at different input power levels.

\begin{tabular}{|c||c|c||c|c||c|c||}
\hline $\begin{array}{c}\text { Dispersion } \\
\text { Compensation } \\
\text { Technique }\end{array}$ & \multicolumn{2}{|c||}{ Symmetrical-DCF } & \multicolumn{2}{|c||}{ FBG } & \multicolumn{2}{c||}{ CFBG } \\
\hline $\begin{array}{c}\text { Input Power } \\
\text { Level }\end{array}$ & $\mathbf{2 . 5 ~ G b / s}$ & $\mathbf{5 ~ G b / s}$ & $\mathbf{2 . 5} \mathbf{~ G b} / \mathbf{s}$ & $\mathbf{5 ~ G b} / \mathbf{s}$ & $\mathbf{2 . 5} \mathbf{~ G b} / \mathbf{s}$ & $\mathbf{5 ~ G b} / \mathbf{s}$ \\
\hline \hline $\mathbf{- 5 ~ d B m}$ & 71.86 & 68.41 & 71.86 & 68.41 & 71.86 & 68.41 \\
\hline $\mathbf{0 ~ d B m}$ & 71.86 & 68.41 & 71.86 & 68.41 & 71.86 & 68.41 \\
\hline $\mathbf{5 ~ d B m}$ & 71.86 & 68.41 & 71.86 & 68.41 & 71.86 & 68.41 \\
\hline $\mathbf{1 0 ~ d B m}$ & 71.86 & 68.41 & 71.86 & 68.41 & 71.86 & 68.41 \\
\hline $\mathbf{1 5} \mathbf{~ d B m}$ & 71.86 & 68.41 & 71.86 & 68.41 & 71.86 & 68.41 \\
\hline
\end{tabular}

Table (11): The SNR of channel 1:193.1 THz for Symmetrical-DCF, FBG and CFBG dispersion mitigation techniques using NRZ format over $100 \mathrm{~km}$ length with data rates 2.5 and $5 \mathrm{~Gb} / \mathrm{s}$ at different input power levels.

\begin{tabular}{|c|c|c|c|c|c|c|}
\hline \multirow{2}{*}{$\begin{array}{c}\text { Dispersion } \\
\text { Compensation } \\
\text { Technique } \\
\begin{array}{c}\text { Input Power } \\
\text { Level }\end{array}\end{array}$} & \multicolumn{2}{|c|}{ Symmetrical-DCF } & \multicolumn{2}{|c|}{ FBG } & \multicolumn{2}{|c|}{ CFBG } \\
\hline & $2.5 \mathrm{~Gb} / \mathrm{s}$ & $5 \mathrm{~Gb} / \mathrm{s}$ & $2.5 \mathrm{~Gb} / \mathrm{s}$ & $5 \mathrm{~Gb} / \mathrm{s}$ & $2.5 \mathrm{~Gb} / \mathrm{s}$ & $5 \mathrm{~Gb} / \mathrm{s}$ \\
\hline$-5 \mathrm{dBm}$ & 46.93 & 42.96 & 49.45 & 43.49 & 45.06 & 40.41 \\
\hline $0 \mathrm{dBm}$ & 52.29 & 48.23 & 56.76 & 49.79 & 50.49 & 46.27 \\
\hline $5 \mathrm{dBm}$ & 57.50 & 53.37 & 62.03 & 55 & 55.74 & 51.46 \\
\hline $10 \mathrm{dBm}$ & 62.62 & 58.45 & 67.18 & 60.11 & 60.87 & 56.56 \\
\hline $15 \mathrm{dBm}$ & 67.69 & 63.49 & 72.26 & 65.18 & 65.95 & 61.62 \\
\hline
\end{tabular}




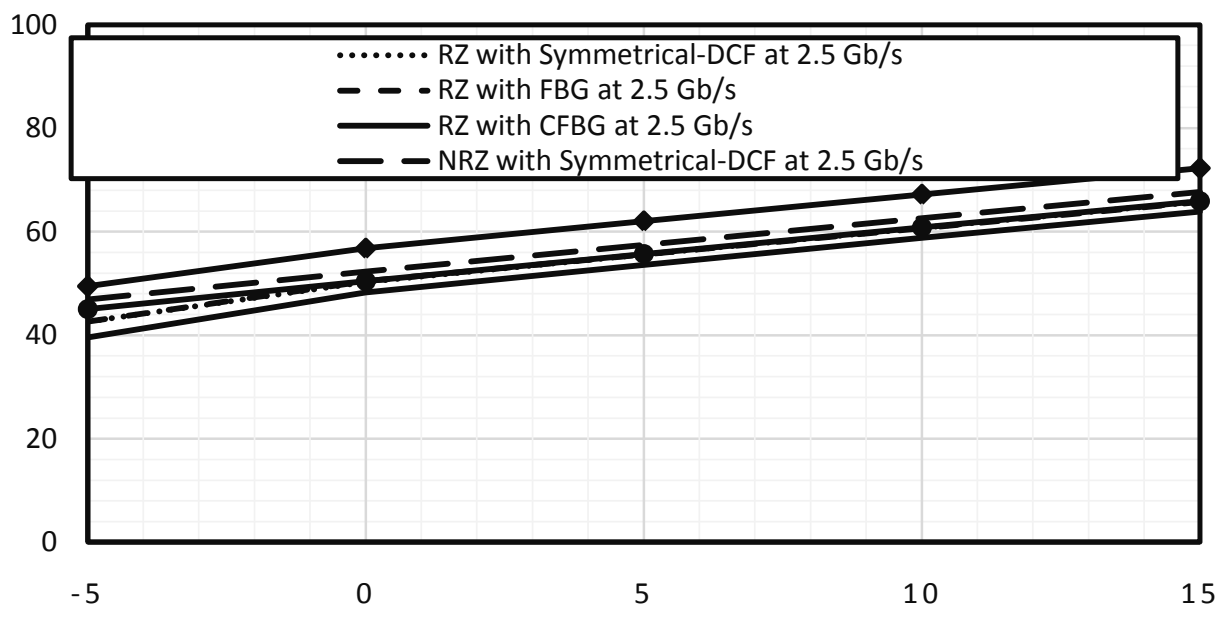

Figure (4) The SNR of channel 1 (193.1 THz) for Symmetrical-DCF, FBG and CFBG dispersion compensation techniques utilizing RZ and NRZ modulation formats over $100 \mathrm{~km}$ fiber length with data rate $2.5 \mathrm{~Gb} / \mathrm{s}$ at different input power levels.

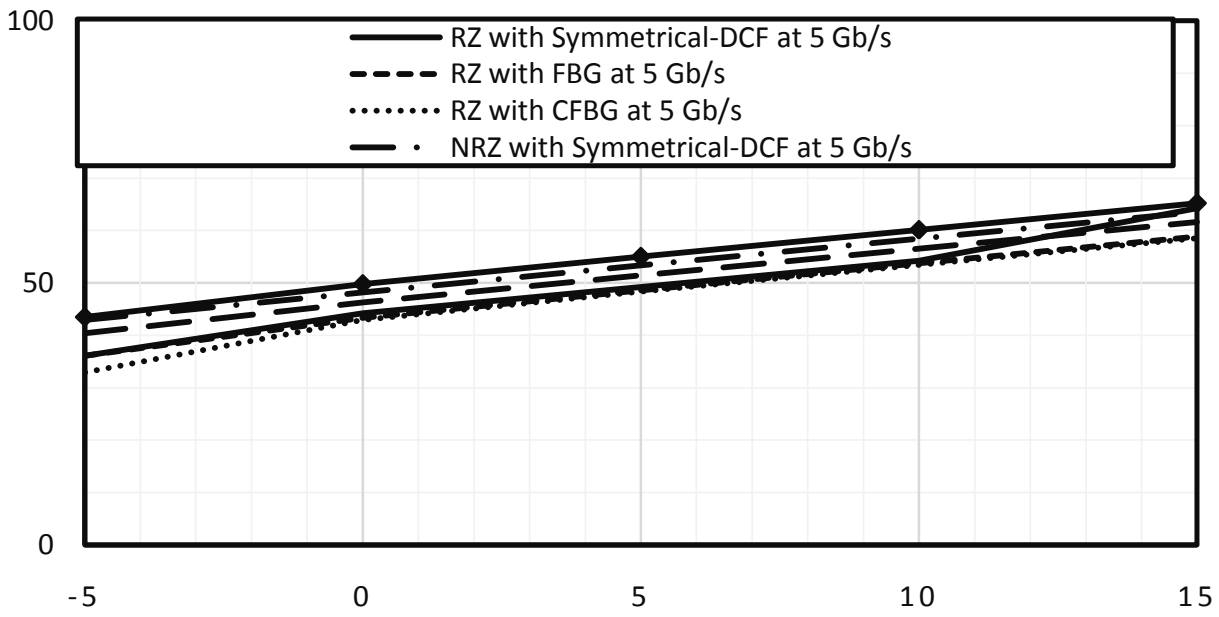

Figure (5) The SNR of channel 1 (193.1 THz) for Symmetrical-DCF, FBG and CFBG dispersion compensation techniques utilizing RZ and NRZ modulation formats over $100 \mathrm{~km}$ fiber length with data rate $5 \mathrm{~Gb} / \mathrm{s}$ at different input power levels.

X) The systems utilizing FBG and symmetrical-DCF achieve better performance in terms of higher SNR following by those that using CFBG.

XI) The OSNR does not change as explained in earlier discussion. As the data rate is increasing, the system performance is reduced as indicated previously.

\section{Conclusion}

The 16-channels DWDM network is implemented by Optisystem. The performance is compared for different dispersion compensation techniques; Symmetrical-DCF, FBG and CFBG. FBG as dispersion compensator offer better performance and larger Q-factor especially for longer transmission distance. FBG achieved Q-factor of approximately 38 and 62 which are the larger Q-factor values compared to other dispersion compensation methods at data rate of $2.5 \mathrm{~Gb} / \mathrm{s}$ over $200 \mathrm{~km}$ fiber length for NRZ and RZ respectively. Whereas, it achieved Q-factor of approximately 31 and 70 which are the larger Q-factor values compared to other dispersion compensation methods at data rate of $5 \mathrm{~Gb} / \mathrm{s}$ over $200 \mathrm{~km}$ fiber length for NRZ and $\mathrm{RZ}$ respectively.
The systems using FBG as dispersion compensator show better performance especially for longer transmission distance and dispersion is compensated perfectly. FBGs are recommended for utilizing in long-haul DWDM networks although they are most costly and more complex in fabrication. It is revealed some facts which are verified and summarized in the following. As the transmission distance increases, the signal quality and system performance are degraded obviously due to pule dispersion. When using symmetrical-DCF with RZ scheme, the SNR is approximately $55 \mathrm{~dB}$ and $26 \mathrm{~dB}$ for fiber lengths of $100 \mathrm{~km}$ and $200 \mathrm{~km}$ respectively at $2.5 \mathrm{~Gb} / \mathrm{s}$. Whereas when using FBG with RZ format, it is approximately $55 \mathrm{~dB}$ and $43 \mathrm{~dB}$ for fiber lengths of $100 \mathrm{~km}$ and $200 \mathrm{~km}$ respectively at 2.5 $\mathrm{Gb} / \mathrm{s}$. As the data rate increases, the performance is reduced adversely due to pulse broadening causing interference with adjacent channels. When using symmetrical-DCF with NRZ scheme, the SNR is approximately $57 \mathrm{~dB}$ and $53 \mathrm{~dB}$ for data rates of $2.5 \mathrm{~Gb} / \mathrm{s}$ and $5 \mathrm{~Gb} / \mathrm{s}$ respectively over $100 \mathrm{~km}$ fiber length. Whereas when using FBG with NRZ format, it is approximately $62 \mathrm{~dB}$ and $55 \mathrm{~dB}$ for data rates of $2.5 \mathrm{~Gb} / \mathrm{s}$ and $5 \mathrm{~Gb} / \mathrm{s}$ respectively over $100 \mathrm{~km}$ fiber length. As the input power level is increasing, the performance is enhanced strongly because of the compensation for the power loss. Finally, the systems using RZ format provides better 
performance than those that using NRZ, since RZ is superior to NRZ format.

\section{References}

[1] P. Kaur, H. Sarangal, "Simulative Investigation and Comparison of $32 \times 40$ Gbps DWDM System Using Different Dispersion Compensation," Int. J. of Adv. Res. in Comp. Sci. \& Software Eng. (IJARCSSE), vol. 6, no. 4, pp.489 - 494, 2016.

[2] V. Senthamizhselvan, et al., "Performance Analysis of DWDM Based Fiber Optic Communication with Different Modulation Schemes and Dispersion Compensation Fiber, " Int. J. of Research in Eng. \& Tech. (IJRET), vol. 03, no. 3, pp. 287 - 290, March 2014.

[3] A. Bhardwaj, G. Soni, "Performance Analysis of 20 Gbps Optical Transmission System Using Fiber Bragg Grating," Int. J. of Scientific \& Research Pub. (IJSRP), vol. 5, no. 1, pp. 1 - 4, Jan. 2015.

[4] Meenakshi, et al., "Comparative Analysis of Different Dispersion Compensation Techniques on 40 Gbps DWDM System," Int. J. of Technol. Enhancements \& Emerging Eng. Research (IJTEEE), vol. 3, no. 6 , pp. $34-38,2015$.

[5] J. Choudhary, et al., "Comparative analysis of DWDM system using different modulation and dispersion compensation techniques at different bit rates," Int. J. of Adv. Research in Computer \& Communication Eng. (IJARCCE), vol. 3, no. 5, pp. $6512-6518$, May 2014

[6] M. Kaur, H. Sarangal, "Performance Comparison of Pre-, Postand Symmetrical-Dispersion Compensation Techniques using DCF on 40Gbps WDM System," Int. J. of Advanced Research in Electronics and Communication Engineering (IJARECE), vol. 4, no. 3, pp. 494 - 496, March 2015.

[7] Bo-ning HU, Wang Jing, Wang Wei, Rui-mei Zhao, "Analysis on Dispersion Compensation with DCF based on Optisystem, " IEEE 2nd Int. Conf. on Industrial \& Information Sys. (IIS 2010), vol. 2, pp. $40-43,2010$.

[8] M. Kaur, H. Sarangal, P. Bagga, "Dispersion Compensation with Dispersion Compensating Fibers (DCF)," Int. J. of Advanced Research in Computer and Communication Engineering (IJARCCE), vol. 4, no. 2, pp. 354 - 356, February 2015.

[9] M. Kaur, H. Sarangal, "Simulative Investigation of 32x10, 32x20 and $32 \times 40 \mathrm{~Gb} / \mathrm{s}$ DWDM Systems with Dispersion Compensating Fibers," International Journal of Signal Processing, Image Processing and Pattern Recognition (IJSIP), vol. 8, no. 8, pp. 127 134, 2015.

[10] M. Sharma, P. K. Raghav, R. Chaudhary, A. Sharma, "Analysis on Dispersion Compensation in WDM Optical Network using Pre, Post and Symmetrical DCF based on Optisystem," MIT International Journal of Electronics and Communication Engineering, vol. 4, no. 1, pp. 58 - 63, Jan. 2014.

[11] E. Ibrahim Essa, "Software Simulation the Hybrid Dispersion Compensation Schemes Based on the $16 \times 40 \mathrm{~Gb} / \mathrm{s}$ DWDM Using $R Z$ Modulation Format," Int. J. of Advanced Research in Computer Science and Software Eng. (IJARCSSE), vol. 2, no. 8, pp. $202-208$, Nov. 2012.

[12] Z. Hu, S. Kartalopoulos, "Simulation models and Evaluation of Pre- and Post-Dispersion Compensation of DWDM Links Using a Bidirectional DCF with FBG Reflectors, " The $9^{\text {th }}$ World Scientific \& Eng. Acad. \& Society (WSEAS), Int. Conf. on Comm., No. 38, Wisconsin, USA, 2005.

[13] U. Bansal, K. Kaur, "Capacity Enhancement of DWDM system using EDFA and DCF with narrow channel spacing," Int. J. of Appl. Sci. \& Eng. Res.(IJASER), vol. 4, no. 1, pp. 147-150, Feb. 2015.

[14] M. Sharma, P. K. Raghav, R. Chaudhary, A. Sharma, "Analysis on Dispersion Compensation in WDM Optical Network using Pre, Post and Symmetrical DCF based on Optisystem," MIT International Journal of Electronics and Communication Engineering, vol. 4, no. 1, pp. 58 - 63, Jan. 2014.

[15] Meenakshi, Jyotsana, Jyoteesh Malhotra, "Comparative Analysis of Different Dispersion Compensation Techniques On 40 Gbps DWDM System," International Journal of Technology Enhancements and Emerging Engineering Research (IJTEEE), vol. 3, no. 06 , pp. $34-38,2015$.
[16] M. Kaur, H. Sarangal, P. Bagga, "Dispersion Compensation with Dispersion Compensating Fibers (DCF)," Int. J. of Advanced Research in Computer and Communication Engineering (IJARCCE), vol. 4, no. 2, pp. 354 - 356, February 2015.

[17] D. Dey, Neha, "Compensation in Optical Fiber WDM System Using Different Compensation Techniques,” Int. J. of Advanced Res. in Computer Science and Software Eng. (IJARCSSE), vol. 4, no. 5, pp. 744 - 751, May 2014.

[18] K. Kumar, A. K.Jaiswal, M. Kumar and N. Agrawal, "Performance Analysis of dispersion compensation using Fiber Bragg Grating $(F B G)$ in Optical Communication," Int. J. of Current Engineering and Technology (IJCET), vol. 4, no. 3, pp. 16 -30, June 2014.

[19] S. Kumar, Prof. A. K. Jaiswal, Er. Mukesh Kumar, Er. Rohini Saxena, "Performance Analysis of Dispersion Compensation in Long Haul Optical Fiber with DCF, " IOSR J. of Electronics and Communication Eng. (IOSR - JECE), vol. 6, no. 6, pp. 19 - 23, Jul. - Aug. 2013.

[20] N. M. Nawawi, "Dispersion Compensation Dense Wavelength Division Multiplexing (DC-DWDM) for Nonlinearity Analysis at Various Propagation Distance and Input Power, " IEEE Int. Conf. on Computer, Communication, and Control Technology (I4CT 2015), pp. 21 -23, April 2015.

[21] V. Bobrovs, S. Spolitis and G. Ivanovs, "Comparison of Chromatic Dispersion Compensation Techniques for WDM-PON solution," IEEE, 2nd Baltic Congress on Future Internet Communications, 2012.

[22] Yin, Xin, et al., "Performance Evaluation of Single Carrier 40Gbit/s Downstream for Long-Reach Passive Optical Networks," IEEE International Conference on Optical Network Design and Modeling, Stockholm, Sweden, 19 May, 2014.

[23] K. Kumar, A. K.Jaiswal, M. Kumar and N. Agrawal, "Performance Analysis of dispersion compensation using Fiber Bragg Grating ( $F B G)$ in Optical Communication," Int. J. of Current Engineering and Technology (IJCET), vol. 4, no. 3, pp. 16 -30 , June 2014.

[24] Neha and R. L Sharma, "Performance Analysis of 8-Channel WDM System using Symmetrical DCF and Optigrating," International Journal of New Trends in Electronics and Communication (IJNTEC), vol. 2, no. 4, June 2014.

[25] Aashima Bhardwaj, Gaurav Soni, "performance Analysis of 20Gbps Optical Transmission System Using Fiber Bragg Grating," International Journal of Scientific and Research Publications (IJSRP), vol. 5, no. 1, pp. 1-4, January 2015.

[26] Kaushal Kumar, A. K. Jaiswal, Mukesh Kumar and Nilesh Agrawal, "Performance Analysis of dispersion compensation using Fiber Bragg Grating (FBG) in Optical Communication," International Journal of Current Engineering and Technology (IJCET), vol. 4, no. 3, pp. 1527 - 1531, June 2014.

[27] P. Spalevic, D. Milic, B. Jaksic, M. Petrovic, I. Temelkovski, "Simulation influence of the thermal noise of PIN photodetector on performance DWDM optical network," XLVII Int. Scientific Conf. on Information, Comm. and Energy Systems and Tech., ICEST 2012, Sofia, vol. 2, pp. 315 - 318, 28-30 June 2012. 